This is the peer reviewed version of the following article: Partridge JS, Crichton S, Biswell E, Harari D, Martin FC, Dhesi JK. Measuring the distress related to delirium in older surgical patients and their relatives. International journal of geriatric psychiatry. $2019 \mathrm{Jul} ; 34(7): 1070-7$, which has been published in final form at https://doi.org/10.1002/gps.5110.

This article may be used for non-commercial purposes in accordance with Wiley Terms and Conditions for Use of Self-Archived Versions 


\section{Measuring the distress related to delirium in older surgical patients and their Relatives}

Judith S.L. Partridge ${ }^{1,2}$, Siobhan Crichton ${ }^{3}$, Elizabeth Biswell ${ }^{1}$, Danielle Harari ${ }^{1,2}$, Finbarr C. Martin ${ }^{4}$, Jugdeep K. Dhesi ${ }^{1,2}$

1 Department of Health and Ageing, Guy's and St Thomas' NHS Foundation Trust, Older Persons Assessment Unit, Ground Floor Bermondsey Wing, Guy's Hospital, London, UK

2 Primary Care and Public Health Sciences, Faculty of Life Sciences and Medicine, King's College London, London, UK

3 MRC Trials Unit, University College London, London, UK

4 Institute of Gerontology, King's College London, London, UK

\section{Abstract}

Objective

Delirium is a common postoperative complication with implications on morbidity and mortality. Less is known about the psychological impact of delirium in patients and relatives. This study aimed to;

1. Quantitatively describe distress related to postoperative delirium in older surgical patients and their relatives using the distress thermometer

2. Examine the association between degree of distress and features of delirium on the Delirium Rating Scale (DRS)

3. Examine the association between recall of delirium and features of delirium on the Delirium Rating Scale (DRS)

\section{Methods}

This prospective study recruited postoperative patients and their relatives following delirium. The distress thermometer was used to examine the degree of distress pertaining to delirium and was conducted during the hospitalisation on resolution of delirium and then at 12 month follow up. Associations between delirium related distress in patient and relative participants and severity and features of delirium ( Delirium Rating Scale) were examined.

\section{Results}

102 patients and 49 relatives were recruited. Median scores on the distress thermometer in patients who recalled delirium were $8 / 10$. Relatives also showed distress (median distress thermometer score 8/10). Associations were observed between severity of and phenotypic features of delirium (delusions, labile affect, agitation). Distress persisted at 12 months in patients and relatives.

\section{Conclusion}

Distress related to postoperative delirium can be measured using a distress thermometer. Alongside approaches to reduce delirium incidence, interventions to minimise distress from postoperative delirium should be sought. Such interventions should be developed through robust research and if effective administered to patients, relatives or carers. 


\section{Introduction}

Delirium is a common postoperative complication occurring in $20 \%$ of hospital inpatients ${ }^{1}$. It has significant implications in terms of increased morbidity and mortality rates ${ }^{2,3}$. Less is understood about patients' experiences of delirium and the longer term psychological morbidity attributable to the condition. Furthermore the psychological consequences of delirium may extend to involve relatives who observe the episode. With the increasing awareness of the importance of patient related outcome measures, describing the delirium experience for both patients and relatives is advocated in the National Institute for Health and Care Excellence (NICE) guideline on delirium ${ }^{4}$.

To date the research examining the delirium experience has been conducted in heterogenous patient populations including critical care survivors, orthogeriatric patients and those receiving end of life care and the quantitative studies have predominantly recruited patients with cancer. Overall these studies suggest that in more than half of cases patients do recall delirium, and that this recollection can be distressing. Distress can be even greater in relatives witnessing delirium and may result in longer term psychological sequelae ${ }^{5-13}$.

Distress related to a diagnosis of cancer has been increasingly described in the oncology literature. It is thought to affect participation in treatment, quality of life and satisfaction with treatment ${ }^{14,15}$. Various brief tools to detect distress in busy clinical environments have been developed and evaluated ${ }^{16,17}$. The distress thermometer (DT) is a self completion tool which asks patients to rate how distressed they have felt in the last week on a scale ranging from 0 (not distressed) to 10 (extremely distressed). It has been incorporated by the National Comprehensive Cancer Network (NCCN) ${ }^{18}$ with a suggested optimal cut off for detecting significant distress of $3^{19}$. When compared against the Hospital Anxiety and Depression Scale (HADS) for detecting anxiety and depression in a sample of patients with cancer, and using a cut point of 3 , the DT showed sensitivity of 0.84 and specificity of 0.80 with AUC $0.69^{16}$.

Whilst prevention of delirium remains paramount, interventions to minimise the distress associated with delirium should be developed in parallel. In order to assess potential interventions to reduce delirium related distress a fuller understanding of the characteristics and impact in the postoperative population is required.

\section{Objectives}

1. To quantitatively describe the distress related to an episode of postoperative delirium in older surgical patients and their relatives using the distress thermometer

2. To examine the association between degree of distress and features of delirium on the Delirium Rating Scale (DRS) ${ }^{20}$ both on resolution of delirium and at 12 month follow up

3. To examine the association between recall of delirium and features of delirium on the Delirium Rating Scale (DRS) 


\section{Methods}

This observational study was set in an inner city teaching hospital in London. Consecutive patients undergoing surgical procedures (gastrointestinal, orthopaedic, urological or vascular) between June 2013 and May 2014 who met the inclusion and exclusion criteria below were eligible for recruitment.

\section{Inclusion criteria}

[A]

\section{Aged 65+}

2. Surgical inpatients following operative procedure (orthopaedic, upper and lower gastrointestinal, vascular, urology)

3. Postoperative delirium, diagnosed using the Confusion Assessment Method $(\mathrm{CAM})^{21}$

[B]

Attending relatives of those patients recruited (if they observed the delirium)

\section{Exclusion criteria}

1. Severe cognitive impairment limiting ability to read, comprehend or complete short questionnaire

2. Patient judged by their attending doctors to be dying and close to death

3. Patients or relatives unable to speak sufficient English to participate in the study without the use of a translator

\section{Recruitment and consent}

Patients who screened positively $(\geq 4)$ on the $4 \mathrm{AT}^{22}$ were assessed for delirium using the CAM. Those without delirium continued to receive daily screening using CAM in case delirium developed during the admission. 4AT negative patients were also flagged to the research team if the usual care team noted clinical features of delirium (e.g. drowsiness, inattention, fluctuation throughout the day). Once delirium was diagnosed, the capacity of the patient to consent to participation in the study was assessed by a research fellow or nurse in accordance with the Mental Capacity Act (2005). Patients with capacity signed a written consent form after verbal and written explanation of the study. Those who lacked capacity were managed according to sections 30-34 of the Mental Capacity Act (2005) with the use of a personal or nominated consultee.

Relatives (one or more) of patient participants were also approached for recruitment and consented, if they had observed the episode of delirium. They were identified through patient participants. Initial contact was either made by the research team on the ward or by telephone.

Tools

The Delirium Rating Scale R98 (DRS R 98) was used to examine features of the delirium. This validated tool is a 16 item scale with a maximum total scale score of 46 points (includes three diagnostic items) and a maximum severity score of 39 points. It has good internal reliability (Cronbach's alpha coefficient 0.9 ) and good interrater reliability ${ }^{22}$. 
The degree of delirium related distress was measured using the distress thermometer described previously. Originally designed to measure cancer related distress this tool was piloted in preliminary work showing acceptability to patients and nursing staff. No adaptions were made to the tool for this study.

Data collection

Once recruited and consented, patients were assessed daily using the Delirium Rating Scale (DRS) in order to ascertain the severity, duration and specific symptoms of delirium e.g. presence of delusional symptoms or motor agitation etc. Drugs used to treat delirium were recorded (antidopaminergics or benzodiazepines). The surgical procedure, nature of admission (i.e. elective or emergency) and baseline demographic and medical data was recorded. In patients who had undergone elective surgery it was noted whether any verbal or written information on the risk of postoperative delirium had been recorded as having been provided.

Following resolution of delirium, participating patients and relatives completed a short questionnaire about their recall and experience of delirium (appendix 3\&4). Patients also underwent brief cognitive assessment using the Montreal Cognitive Assessment (MoCA ${ }^{23}$ and completed a Hospital Anxiety and Depression Score $(\text { HADS })^{24}$ questionnaire. This initial questionnaire and cognitive assessment was undertaken up to a week after delirium resolution whilst the patient was still an inpatient. The questionnaire was repeated at 12 months after resolution of delirium.

Sample size calculation

Using pilot data (examining delirium related distress measured on the distress thermometer in older postoperative patients) the sample size was calculated at 68 patients (based on a standard deviation of 2.1 and a standard error of 1 ). Assuming (based on previous literature ${ }^{5}$ ) that between one half and two thirds of patients will recall the delirium we aimed to recruit 102 patients.

Data analysis

Patient characteristics were summarised as frequency (percentage), mean (standard deviation) or median (interquartile range). Age of patients who recalled delirium was compared to those who did not using the T-test, number of co-morbidities and disease severity compared using the Mann-Whitney test and all other characteristics compared between the two groups using Chi-square or Fisher's exact tests, as appropriate. Correlations between distress score and continuous characteristics (age, number of co-morbidities and disease severity) were assessed using Kendall's Tau-b and distress scores compared across other characteristics using the MannWhitney test for two groups and the Kruskall Wallis test for three or more. Associations between relative distress scores, patient characteristics and disease severity were explored in the same way. Analysis was conducted using data from all participating relatives, followed by a sensitivity analysis where one relative was randomly selected (where two or more relatives provided data relating to the same patient).

Characteristics associated with the odds of remembering delirium were identified using multivariable logistic regression, and then linear regression used models to 
identify characteristics associated with degree of distress among only those who recalled delirium. For both models, factors which had a $p$-value of $<0.1$ in unvariable analysis were carried forward to multivariable models which also adjusted for age. Insignificant variables were then removed using backwards elimination.

In analysis of delirium severity the mean DRS was used. A sensitivity analysis was carried out in which highest DRS scores were used instead. Parameter estimates and p-values were very similar and choice of scoring algorithm did not alter conclusions and so only results using means are presented.

Analysis was conducted using stata 13MP.

\section{Results}

One hundred and thirteen potential patient participants were approached of whom sixty two had capacity to consent. One hundred and two patient participants were recruited into the study (fig 1 ). Nine potential patient participants with capacity declined with the majority of these stating they did not want to discuss the delirium. Two personal consultees declined on behalf of potential patient participants without capacity. Forty three relative participants were approached and all consented to study participation (figure 1).

The relationships between patient characteristics and recall of delirium are summarised in Table 1 . The likelihood of recalling delirium did not differ significantly across any of the patient characteristics.

Table 1 - Patient recall of delirium by patient characteristics

The median distress score on the distress thermometer was 6 [IQR 2-9] and differed significantly between those who did and did not recall delirium (patients who recalled: median $=8$ [4-9] versus $2[0-5]$ in those who did not, $p<0.001$ ). There was also a weak negative correlation between distress score and age in all patients (tau=$0.16, p<0.033$ ) and a slightly weaker, but non-significant correlation in only patients who recalled delirium ( $\mathrm{tau}=-0.14, p=0.118$ ). No association was seen between level of distress and other baseline patient characteristics across the whole group or if those who recalled delirium were analysed separately (table S1). As per our hypothesis, the level of distress was higher in those who recalled delirium. There was no difference in delirium related distress between those patients who received preoperative verbal or written information on the risk of postoperative delirium and those who did not.

The relationships between severity of delirium, recall of delirium and distress are summarised in table 2 . The first columns compare distress scores in those who did and did not recall delirium while the last two summarise the correlation between mean DRS and distress. Perceptual disturbance, delusions and lability of affect were all significantly associated with degree of distress. 
Table 2: Associations between patient recall of delirium/degree of distress and the DRS

Data were collected from 43 relatives of 38 patients. The median level of distress recorded on the distress thermometer in relatives who witnessed delirium was 8/10 [7-9]. Carer distress increased significantly with duration of delirium (tau $=0.307$, $p=0.009)$. DRS severity score $(t=0.363, p=0.002)$ and total score $(0.318, p=0.006)$ were also positively associated with carer distress. The individual features associated with carer distress were lability of affect (tau=0.744, $p=0.021$ ), language (tau $=0.253$, $p=0.034$ ), thought process ( $\operatorname{tau}=0.386, p=0.001$ ), motor agitation (tau $=0.264$, $p=0.001$ ) and orientation (tau $=0.296, p=0.015$ ). In a sensitivity analysis one relative was randomly selected for the five patients where two provided data. Findings were unchanged when analysis was repeated on this subsample (Table S2).

Finally models were fitted to identify factors which were independently associated with patient recall of delirium and distress. Logistic regression was used to identify factors (patient characteristics and DRS items) associated with recall of delirium after adjusting for age. In these models perceptual disturbance was the only factor identified to significantly influence recall of the delirious episode $(O R=1.94,95 \% \mathrm{Cl}$ 1.19-3.17, $p=0.008$ ). Linear models were used to examine features of delirium associated with higher distress scores. Only emergency surgery was significant after adjustment for age (beta=-2.6, 95\% $\mathrm{Cl}-5.2--0.1, \mathrm{p}=0.044$ ).

Next the associations between features of delirium/delirium severity and distress at 6 and 12 months in patients and carers were explored (table 3). In patients, at 12 months the duration of delirium was positively correlated with degree of distress. Orientation and thought process was negatively associated with distress. Though sample sizes are very small it does appear there is a high correlation at both 6 and 12 months between the mean DRS score and distress in carers

Table 3: Associations between degree of distress and the DRS at follow up in patients who recalled delirium and their carers

\section{Discussion}

This is the first study to explore the level of distress related to postoperative delirium in patients and their relatives and describe the features of delirium most associated with delirium related distress. It shows considerable delirium related distress in those who recall postoperative delirium (median score on DT 8/10 [4-9]) with distress scores seen in relatives who observed delirium (median score on DT 8/10 [79.5]). Whilst no associations exist between baseline patient characteristics and delirium related distress, clear associations were observed between the severity of delirium (measured using DRS) and phenotypic features of delirium and level of delirium related distress. Clinical features associated with distress were similar in patients and relatives and include duration of delirium, presence of delusions, abnormal thought processes, labile affect, language disturbance, agitation and disorientation. 
There were limitations to this study. In particular data were only available from relatives of 38 of 102 patients and follow-up data were only provided from seven and 15 patients at 6 and 12 months respectively. Although the available data can give some indication of the long term impact of delirium on distress of patients and carers in the long term, a larger sample would be need to explore this further in order to negate the impact from possible bias due to non-completion of longer term follow up. Furthermore the measurement of the emotional concept of distress is inherently problematic. Attempts to mitigate this were undertaken in this study by using the distress thermometer which has already been validated in the measurement of cancer related distress and is endorsed for use clinically by the National Comprehensive Cancer Network (NCCN). The potential for recruitment bias exists and within this study no conclusive comment can be made on whether those with a traumatic experience of delirium were more or less likely to participate. Of note though, in the co-design of the study, offering an opportunity to discuss the delirium related distress was favoured by both patients and relatives who had experienced postoperative delirium during previous hospital episodes. Finally the lack of a control group is an acknowledged limitation. Whilst this was beyond the scope of this study, previous work has reported that symptoms of anxiety and depression are more prominent in patients following haematopoetic cell transplantation if they suffered from delirium once adjusting for potential confounders including disease severity, comorbidity, steroid usage and pain $[11,12]$.

These findings are in keeping with similar studies in other patient populations especially those with cancer who experience delirium during hospitalisation ${ }^{5}$. However the longer term one year follow up in the present study adds to our understanding of this issue. Whilst numbers were small, predominantly due to death/attrition from study, the negative impact of delirium on the perception of distress appeared to persist at 12 month follow up. This is relevant in terms of both necessary translation of results into clinical services and future research in this field. Delirium related distress is already thought to result in higher rates of symptoms of depression and non-engagement in future treatments ${ }^{14,15}$ so potential interventions to modify this negative consequence of delirium should be developed and evaluated in the clinical setting. At present no 'delirium distress' intervention exists but this should be a focus of future research in this field.

\section{Conclusion}

This study has shown high levels of postoperative delirium related distress in both elective and emergency surgical patients and their relatives who observed the delirium persisting at 12 month follow up. Alongside established efforts to reduce the incidence of delirium attempts should also be made to minimise the impact of this common condition. Such supportive interventions should be derived through robust research methodology and if effective administered clinically to both patients and their relatives or carers. 
Data Availability Statement

The data that support the findings of this study are available from the corresponding author upon reasonable request.

\section{References}

[1] Ryan DJ, O’Regan NA, Ó Caoimh R, Clare J, O’Connor M, Leonard M, et al. Delirium in an adult, acute hospital population: predictors, prevalence and detection. BMJ Open 2013;3:e001772.

[2] Marcantonio ER, Flacker JM, Michaels M, Resnick NM. Delirium is independently associated with poor functional recovery after hip fracture. J Am Geriatr Soc 2000;48(6):618-24.

[3] Edelstein DM, Aharonoff GB, Karp A, Capla EL, Zuckerman JD, Koval KJ. Effect of postoperative delirium on outcome after hip fracture. Clin Orthop Relat Res 2004(422):195-200.

[4] NICE. Delirium : diagnosis, prevention and management CG103. London: National Institute for Health and Clinical Excellence, 2010.

[5]Breitbart W, Gibson C, Tremblay A. The delirium experience: delirium recall and delirium-related distress in hospitalized patients with cancer, their spouses/caregivers, and their nurses. Psychosomatics 2002;43(3):183-94.

[6]O'Malley G, Leonard M, Meagher D, O'Keeffe ST. The delirium experience: a review. J Psychosom Res 2008;65(3):223-8.

[7] Instenes I, Gjengedal E, Eide LSP, Kuiper KKJ, Ranhoff AH, Norekvål TM; CARDELIR Investigators. "Eight Days of Nightmares ... " Octogenarian Patients' Experiences of Postoperative Delirium after Transcatheter or Surgical Aortic Valve Replacement. Heart Lung Circ. 2018;27:260-266.

[8]Jones C, Griffiths RD, Humphris G, Skirrow PM. Memory, delusions, and the development of acute posttraumatic stress disorder-related symptoms after intensive care. Crit Care Med 2001;29(3):573-80.

[9]Grover S, Shah R. Distress due to delirium experience. Gen Hosp Psychiatry 2011. [10]Bruera E, Bush SH, Willey J, Paraskevopoulos T, Li Z, Palmer JL, et al. Impact of delirium and recall on the level of distress in patients with advanced cancer and their family caregivers. Cancer 2009;115(9):2004-12.

[11]Fann JR, Alfano CM, Roth-Roemer S, Katon WJ, Syrjala KL. Impact of delirium on cognition, distress, and health-related quality of life after hematopoietic stem-cell transplantation. J Clin Oncol 2007;25(10):1223-31.

[12]Basinski JR, Alfano CM, Katon WJ, Syrjala KL, Fann JR. Impact of delirium on distress, health-related quality of life, and cognition 6 months and 1 year after hematopoietic cell transplant. Biol Blood Marrow Transplant 2010;16(6):824-31. [13]Davydow DS. Symptoms of depression and anxiety after delirium. Psychosomatics 2009;50(4):309-16.

[14]Bui QU, Ostir GV, Kuo YF, Freeman J, Goodwin JS. Relationship of depression to patient satisfaction: findings from the barriers to breast cancer study. Breast Cancer Res Treat 2005;89(1):23-8.

[15]Stark D, Kiely M, Smith A, Velikova G, House A, Selby P. Anxiety disorders in cancer patients: their nature, associations, and relation to quality of life. J Clin Oncol 2002;20(14):3137-48. 
[16]Baken DM, Woolley C. Validation of the Distress Thermometer, Impact Thermometer and combinations of these in screening for distress. Psychooncology 2011;20(6):609-14.

[17]Roth AJ, Kornblith AB, Batel-Copel L, Peabody E, Scher HI, Holland JC. Rapid screening for psychologic distress in men with prostate carcinoma: a pilot study. Cancer 1998;82(10):1904-8.

[18]https://www.nccn.org/patients/resources/life_with_cancer/pdf/nccn_distress_t hermometer.pdf

[19] Cutillo A, O'Hea E, Person SD, Lessard D, Harralson TL, Boudreaux E. The Distress Thermometer: cutoff points and clinical use. Oncology Nursing Forum 2017; 44: 1-9.

[20] Trzepacz P, Mittal D, Torres R, Kanary K, Norton J, Jimerson N. Validation of the Delirium Rating Scale-Revised-98: Comparison with the Delirium Rating Scale and the Cognitive Test for Delirium. The Journal of neuropsychiatry and clinical neurosciences 2001;13:229-42.

[21] Inouye SK, van Dyck CH, Alessi CA, Balkin S, Siegal AP, Horwitz RI. Clarifying confusion: the confusion assessment method. A new method for detection of delirium. Ann Intern Med 1990;113:941-8.

[22] Bellelli G, Morandi A, Davis DH, Mazzola P, Turco R, Gentile S et al. Validation of the 4AT, a new instrument for rapid delirium screening: a study in 234 hospitalised older people. Age Ageing. 2014; 43:496-502.

[23] Nasreddine ZS, Phillips NA, Bedirian V, Charbonneau S, Whitehead V, Collin I, et al. The Montreal Cognitive Assessment, MoCA: a brief screening tool for mild cognitive impairment. J Am Geriatr Soc. 2005;53:695-9.

[24] Zigmond AS, Snaith RP. The Hospital Anxiety and Depression Scale. Acta Psychiatr Scand. 1983;67:361-70. 


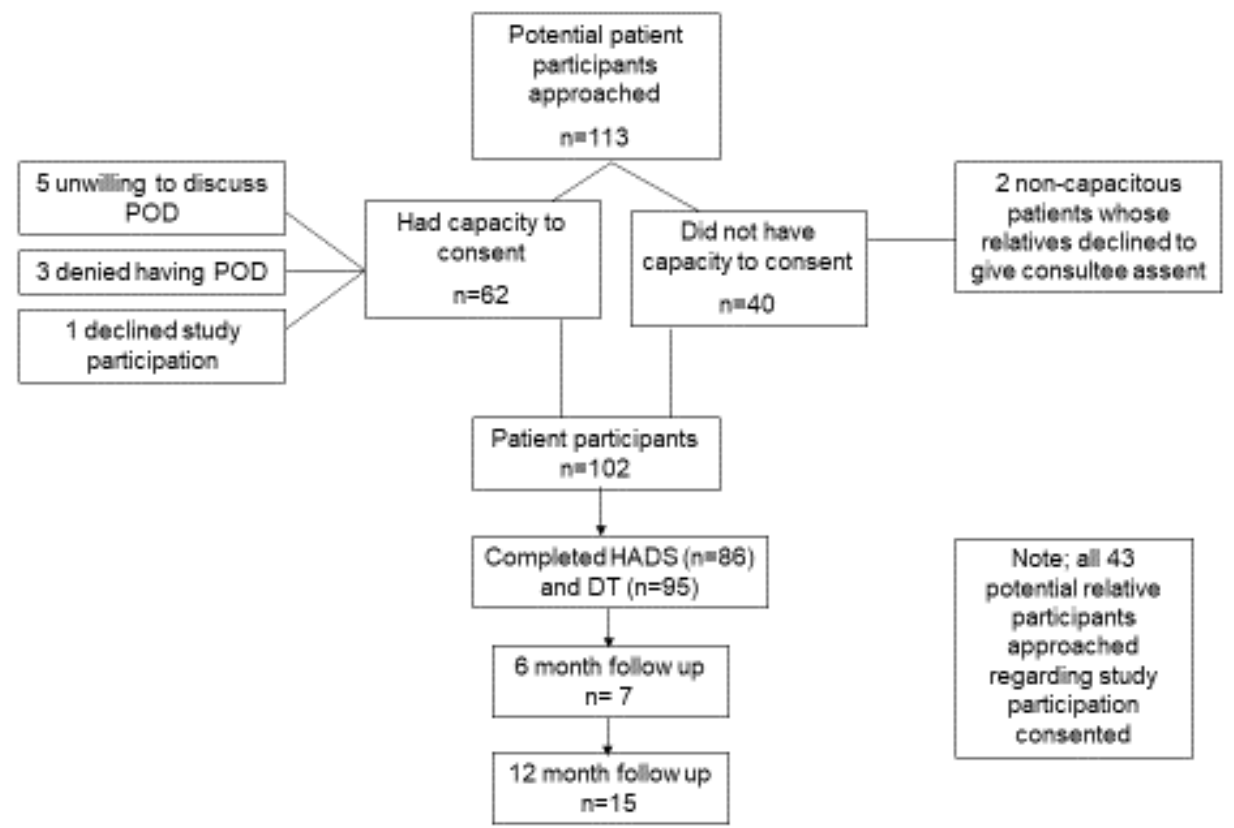

Figure 1. Recruitment into study 
Table 1 - Patient recall of delirium by patient characteristics

\begin{tabular}{|c|c|c|c|c|}
\hline & All, n (\%) & $\begin{array}{c}\text { Did not } \\
\text { recall } \\
\text { delirium, } \\
\mathrm{n}(\%)\end{array}$ & $\begin{array}{c}\text { Recalled } \\
\text { delirium, } \\
\text { n (\%) }\end{array}$ & $\begin{array}{c}\mathrm{p}- \\
\text { value }\end{array}$ \\
\hline All & 102 & 27 & 67 & \\
\hline Age, mean(sd) & $78.7(7.3)$ & $80.0(7.5)$ & $78.5(7.3)$ & 0.383 \\
\hline White Ethnicity & $87(88.8)$ & $23(85.2)$ & $56(85.6)$ & 0.999 \\
\hline $12+$ years in education & 14(16.9) & $4(14.8)$ & $10(14.9)$ & 0.950 \\
\hline Male & $69(67.7)$ & $16(59.3)$ & $47(70.1)$ & 0.310 \\
\hline Current smoker & $17(17.0)$ & $5(18.5)$ & $10(14.9)$ & 0.894 \\
\hline \multicolumn{5}{|l|}{ Alcohol consumption (per week) } \\
\hline None & $41(42.7)$ & $14(51.9)$ & $24(35.8)$ & 0.386 \\
\hline$<15$ units (f) or $<22$ units (m) & $35(36.5)$ & $7(25.9)$ & $25(37.3)$ & \\
\hline$>14$ units $(f)$ of $>21$ units $(m)$ & $20(20.8)$ & $5(18.5)$ & $13(19.4)$ & \\
\hline Number of co-morbidities, median (IQR) & $5.5(4-8)$ & $6(4-8)$ & $6(4-8)$ & 0.987 \\
\hline Elective surgery & $49(48.0)$ & $13(48.1)$ & $32(47.8)$ & 0.973 \\
\hline \multicolumn{5}{|l|}{ Surgical subspecialty } \\
\hline Urological & $12(11.8)$ & $2(7.4)$ & $7(10.4)$ & 0.296 \\
\hline GI & $21(50.6)$ & $6(22.2)$ & 13(19.4) & \\
\hline Vascular & $50(49.0)$ & $11(40.7)$ & $36(53.7)$ & \\
\hline Orthopaedic & $17(16.7)$ & $6(22.2)$ & $11(16.4)$ & \\
\hline Head and neck & $1(1.0)$ & $1(3.7)$ & 0 & \\
\hline Gynaecological & $1(1.0)$ & $1(3.7)$ & 0 & \\
\hline History of cognitive impairment & $77(75.5)$ & 19(70.3) & $52(77.6)$ & 0.596 \\
\hline Recalled delirium & $67(71.3)$ & NA & NA & \\
\hline Drugs used to treat delirium & $33(32.4)$ & $10(37.0)$ & $18(26.8)$ & 0.332 \\
\hline Patient warned of possibility of delirium & $14(14.9)$ & $5(18.5)$ & $9(13.4)$ & \\
\hline
\end{tabular}


Table 2: Associations between patient recall of delirium/degree of distress and the DRS

\begin{tabular}{|c|c|c|c|c|c|c|}
\hline & $\begin{array}{c}\text { All, } \\
\text { median } \\
\text { (IQR) or } \\
\text { mean (sd) }\end{array}$ & $\begin{array}{c}\text { Did not } \\
\text { recall } \\
\text { delirium, } \\
\text { median (IQR) } \\
\text { or mean }(\mathrm{sd})\end{array}$ & $\begin{array}{l}\text { Recalled } \\
\text { delirium, } \\
\text { median } \\
\text { (IQR) or } \\
\text { mean (sd) }\end{array}$ & $\begin{array}{c}p- \\
\text { value }\end{array}$ & $\begin{array}{c}\text { Distress } \\
* \\
\text { Kendall } \\
\text { s tau }\end{array}$ & $\begin{array}{c}\mathrm{p}- \\
\text { value }\end{array}$ \\
\hline Delirium duration & $4(2-7)$ & $5(2-7)$ & $3(2-5)$ & 0.484 & 0.14 & 0.142 \\
\hline DRS (mean) Severity score & $19.8(6.6)$ & $18.7(5.5)$ & $20.3(6.9)$ & 0.280 & 0.202 & 0.023 \\
\hline \multicolumn{7}{|l|}{ DRS (mean) severity items } \\
\hline Sleep wake cycle & $2(1-2)$ & $2(1-2)$ & $2(1-2)$ & 0.632 & 0.101 & 0.290 \\
\hline Perpetual disturbance & $\begin{array}{c}1.2(0.7- \\
2.3)\end{array}$ & $1(0-2)$ & $1.6(1-3)$ & 0.010 & 0.012 & 0.903 \\
\hline Delusion & $1(0.5-2)$ & $0.7(0-1.7)$ & $1(0.5-2)$ & 0.029 & 0.198 & 0.034 \\
\hline Lability of affect & $2(1.3-2.2)$ & $2(1-2)$ & $2(1.3-2.2)$ & 0.275 & 0.238 & 0.012 \\
\hline Language & $1(0.3-1)$ & $0.9(0.3-1)$ & $1(0.3-1.4)$ & 0.374 & -0.009 & 0.928 \\
\hline Thought process & $2(1.7-3)$ & $2(1.5-2.3)$ & $2(1.7-3)$ & 0.076 & 0.152 & 0.110 \\
\hline Motor agitation & $1.5(0.6-2)$ & $1.5(0.5-2)$ & $1.5(0.5-2)$ & 0.751 & 0.126 & 0.174 \\
\hline Motor retardation & $0.5(0-1.5)$ & $1.5(0.5-2.8)$ & $1(0-2)$ & 0.270 & -0.102 & 0.287 \\
\hline Orientation & $2(1.5-2)$ & $2(1.5-2)$ & $2(1.5-2)$ & 0.618 & -0.015 & 0.877 \\
\hline Attention & $2(1.6-2.7)$ & $2(1.5-2.7)$ & $2(1.5-3)$ & 0.831 & 0.053 & 0.582 \\
\hline Short term memory & $2(1.5-3)$ & $2(1.5-3)$ & $2(1.5-2.7)$ & 0.840 & 0.142 & 0.135 \\
\hline Long term memory & $0(0-1)$ & $0(0-1)$ & $0(0-0.7)$ & 0.479 & 0.322 & 0.001 \\
\hline Visio-spatial & $1.6(1-2)$ & $1.8(1-2.8)$ & $1.6(1-2)$ & 0.464 & 0.131 & 0.164 \\
\hline $\begin{array}{l}\text { Temporal onset of symptoms } \\
\text { score }\end{array}$ & $3(2-3)$ & $3(2-3)$ & $3(2-3)$ & 0.387 & 0.001 & 1.000 \\
\hline Fluctuation of symptoms score & $1(1-2)$ & $1(1-2)$ & $1(1-2)$ & 0.089 & 0.174 & 0.099 \\
\hline Physical disorder score & $2(2-2)$ & $2(2-2$ & $2(2-2)$ & 0.033 & -0.193 & 0.079 \\
\hline DRS (mean) Total Score & $26.0(5.8)$ & $24.2(6.1)$ & $26.3(5.8)$ & 0.122 & 0.170 & 0.063 \\
\hline
\end{tabular}

*Patients who recalled delirium only 
Table 3: Associations between DRS and degree of distress at follow up in patients who recalled delirium and their carers

\begin{tabular}{|c|c|c|c|c|c|c|c|c|}
\hline & \multicolumn{4}{|c|}{ Patient Distress* } & \multicolumn{4}{|c|}{ Carer distress } \\
\hline & \multicolumn{2}{|c|}{6 months, $n=7$} & \multicolumn{2}{|c|}{$\begin{array}{c}12 \text { months, } \\
\mathrm{n}=15\end{array}$} & \multicolumn{2}{|c|}{6 months, $n=5$} & \multicolumn{2}{|c|}{12 months, $\mathrm{n}=6$} \\
\hline & $\begin{array}{l}\text { Kendall } \\
\text { s tau }\end{array}$ & $\begin{array}{c}p- \\
\text { value }\end{array}$ & $\begin{array}{l}\text { Kenda } \\
\text { Ils tau }\end{array}$ & $\begin{array}{c}p- \\
\text { value }\end{array}$ & $\begin{array}{l}\text { Kendall } \\
\text { s tau }\end{array}$ & p-value & $\begin{array}{l}\text { Kendall } \\
\text { s tau }\end{array}$ & $p$-value \\
\hline Baseline distress & -0.55 & 0.125 & 0.177 & 0.416 & 0.134 & 1.00 & 0.276 & 0.566 \\
\hline Delirium duration & -0.15 & 0.759 & 0.453 & 0.041 & 0.252 & 0.776 & 0.356 & 0.492 \\
\hline $\begin{array}{l}\text { DRS (mean) Severity score } \\
\text { DRS (mean) severity items }\end{array}$ & -0.450 & 0.219 & -0.183 & 0.391 & 0.756 & 0.154 & 0.714 & 0.080 \\
\hline Sleep wake cycle & -0.067 & 1.000 & -0.126 & 0.613 & 0.134 & 1.000 & -0.214 & 0.697 \\
\hline Perpetual disturbance & -0.231 & 0.612 & -0.011 & 1.000 & 0.429 & 0.533 & -0.414 & 0.339 \\
\hline Delusion & -0.103 & 0.877 & 0.089 & 0.715 & 0.429 & 0.533 & 0.297 & 0.552 \\
\hline Lability of affect & 0.000 & 1.000 & 0.123 & 0.599 & 0.756 & 0.154 & 0.643 & 0.120 \\
\hline Language & -0.418 & 0.304 & -0.298 & 0.185 & 0.252 & 0.776 & -0.309 & 0.545 \\
\hline Thought process & -0.264 & 0.526 & -0.461 & 0.038 & 0.429 & 0.533 & 0.077 & 1.000 \\
\hline Motor agitation & -0.550 & 0.125 & -0.262 & 0.233 & 0.252 & 0.776 & 0.661 & 0.159 \\
\hline Motor retardation & -0.109 & 0.873 & 0.057 & 0.831 & -0.143 & 1.000 & 0.232 & 0.682 \\
\hline Orientation & -0.418 & 0.304 & -0.475 & 0.034 & 0.714 & 0.213 & -0.232 & 0.682 \\
\hline Attention & -0.380 & 0.336 & -0.121 & 0.623 & 0.571 & 0.350 & 0.161 & 0.835 \\
\hline Short term memory & -0.685 & 0.059 & -0.241 & 0.294 & 0.267 & 0.769 & 0.178 & 0.819 \\
\hline Long term memory & -0.194 & 0.721 & -0.041 & 0.903 & 0.378 & 0.693 & 0.445 & 0.360 \\
\hline Visio-spatial & -0.513 & 0.162 & -0.057 & 0.833 & 0.252 & 0.776 & 0.694 & 0.106 \\
\hline $\begin{array}{l}\text { Temporal onset of symptoms } \\
\text { score }\end{array}$ & 0.000 & 1.000 & 0.295 & 0.233 & 0.000 & 1.000 & 0.598 & 0.235 \\
\hline Fluctuation of symptoms score & -0.194 & 0.721 & 0.233 & 0.351 & -0.378 & 0.693 & 0.756 & 0.100 \\
\hline Physical disorder score & -0.183 & 0.801 & 0.000 & 1.000 & 0.000 & 1.000 & 0.000 & 1.000 \\
\hline DRS (mean) Total Score & -0.586 & 0.095 & -0.140 & 0.540 & 0.756 & 0.154 & 0.857 & 0.032 \\
\hline
\end{tabular}

*Patients who recalled delirium only 
Appendices

Appendix 1 - Table S1 - Patient recall of delirium and degree of distress by patient characteristics

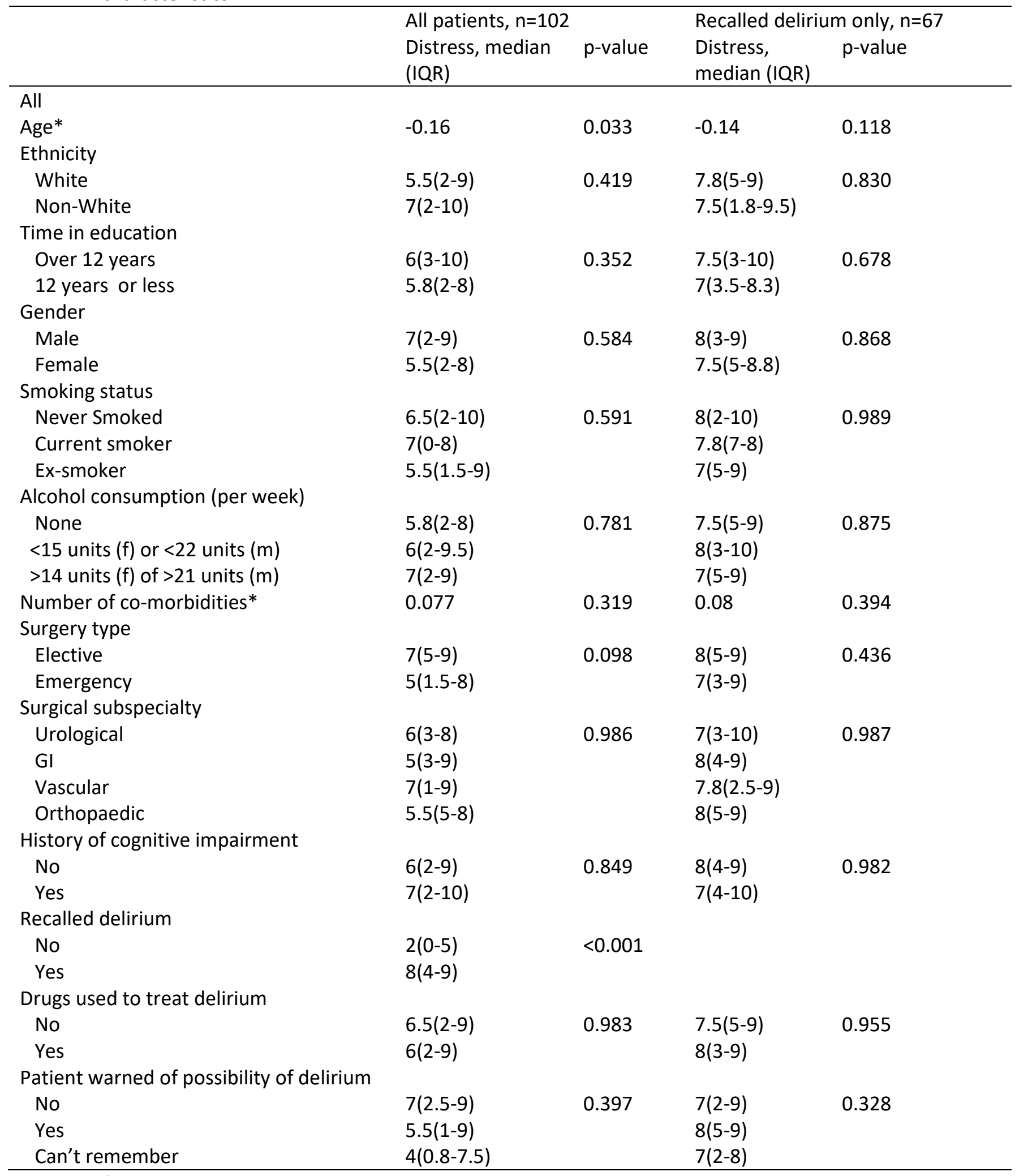

*Kendalls tau-b. 
Appendix 2 - Table S2 - Relationship between relative and patient characteristics and relative distress.

\begin{tabular}{|c|c|c|c|}
\hline & $\begin{array}{l}\text { All, } n(\%) \text { or } \\
\text { median } \\
\text { (IQR) }\end{array}$ & $\begin{array}{l}\text { Distress, } \\
\text { median } \\
\text { (IQR) or } \\
\text { Kendalls } \\
\text { tau }\end{array}$ & p-value \\
\hline All & 43 & $8(7-9.5)$ & \\
\hline \multicolumn{4}{|l|}{ Relationship to patient } \\
\hline Spouse & $18(41.9)$ & $8.5(7-10)$ & 0.478 \\
\hline Son/daughter & $17(39.5)$ & $8(7.5-8)$ & \\
\hline Other & $8(18.6)$ & $7.5(6-9)$ & \\
\hline \multicolumn{4}{|l|}{ Relative warned about delirium } \\
\hline No & $34(81.0)$ & $8(7-10)$ & 0.425 \\
\hline Yes & $8(19.1)$ & $7.5(6-9)$ & \\
\hline \multicolumn{4}{|l|}{ Delirium explained to relative } \\
\hline No/can't remember & $28(65.1)$ & $8(6-10)$ & 0.445 \\
\hline Yes & $15(34.9)$ & $8(7.5-9)$ & \\
\hline \multicolumn{4}{|l|}{ Patient recall of delirium } \\
\hline No & $7(17.5)$ & $8(7.5-10)$ & 0.459 \\
\hline Yes & $33(82.5)$ & $8(7-9)$ & \\
\hline Patient distress & $6(1.8-9)$ & 0.237 & 0.052 \\
\hline Delirium duration & $5(3-11)$ & 0.307 & 0.009 \\
\hline DRS (mean) Severity score* & $21.5(6.9)$ & 0.363 & 0.002 \\
\hline \multicolumn{4}{|l|}{ DRS (mean) severity items } \\
\hline Sleep wake cycle & $2(1-2)$ & 0.252 & 0.039 \\
\hline Perpetual disturbance & $1(1.5-2.5)$ & 0.085 & 0.475 \\
\hline Delusion & $1.3(0.5-2.5)$ & 0.196 & 0.097 \\
\hline Lability of affect & $2(1.3-2.1)$ & 0.274 & 0.021 \\
\hline Language & $1(0.3-1.5)$ & 0.253 & 0.034 \\
\hline Thought process & $2(2-3)$ & 0.386 & 0.001 \\
\hline Motor agitation & $2(0.8-2)$ & 0.264 & 0.027 \\
\hline Motor retardation & $1(0-2)$ & -0.125 & 0.304 \\
\hline Orientation & $2(1.5-2)$ & 0.296 & 0.015 \\
\hline Attention & $2(1.6-3)$ & 0.078 & 0.530 \\
\hline Short term memory & $2(1.5-2.5)$ & 0.182 & 0.132 \\
\hline Long term memory & $0(0-0.5)$ & 0.125 & 0.324 \\
\hline Visio-spatial & $1.8(1.2-2.0)$ & 0.131 & 0.276 \\
\hline Temporal onset of symptoms score & $3(2-3)$ & -0.228 & 0.086 \\
\hline Fluctuation of symptoms score & $2(1-2)$ & -0.003 & 0.990 \\
\hline Physical disorder score & $2(2-2)$ & 0.079 & 0.572 \\
\hline DRS (mean) Total Score* & $26.9(5.0)$ & 0.318 & 0.006 \\
\hline
\end{tabular}

*Summarised as mean (sd) 
URN:

\section{Measuring the distress related to delirium - patient questionnaire}

Thank you for taking the time to complete this questionnaire. As part of a research project we are trying to find out more about how patients and their families and carers feel about some aspects of having an operation.

We estimate that it will take about 5 minutes to complete this survey. There are no right or wrong answers. Your responses are completely anonymous and confidential. They will not be seen by your doctors and nurses. We do not need your name.

When you have completed the questionnaire please hand it back to the researcher.

Thank you very much for your help in filling out the questionnaire. If you would like any further information about this research or if you have any questions at all please email $\mathrm{xxx}$ or call xxx 
URN:

\section{Delirium Experience Questionnaire - patient}

1. Do you remember being confused at all when you were in hospital?
a) Yes
b) No

\section{If you answered 'Yes' to Q1 please go on to answer Q3 and Q4.}

\section{If you answered 'No' to Q1 please go on to answer Q2 and then Q4.}

2. Does it upset you that you can't remember this?

Please mark how distressed you feel on the thermometer below.

0 is 'not at all distressed' and 10 is 'extremely distressed'.

1

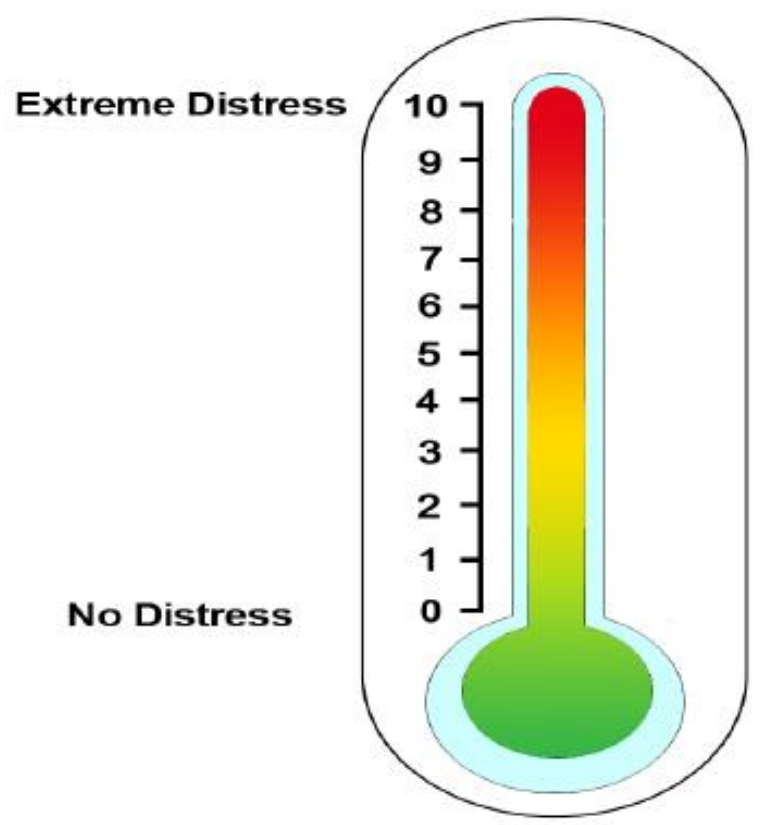


3. How distressed were you by being confused in hospital?

Please mark how distressed you feel related to this confusion on the thermometer below

0 is 'not at all distressed' and 10 is 'extremely distressed'.

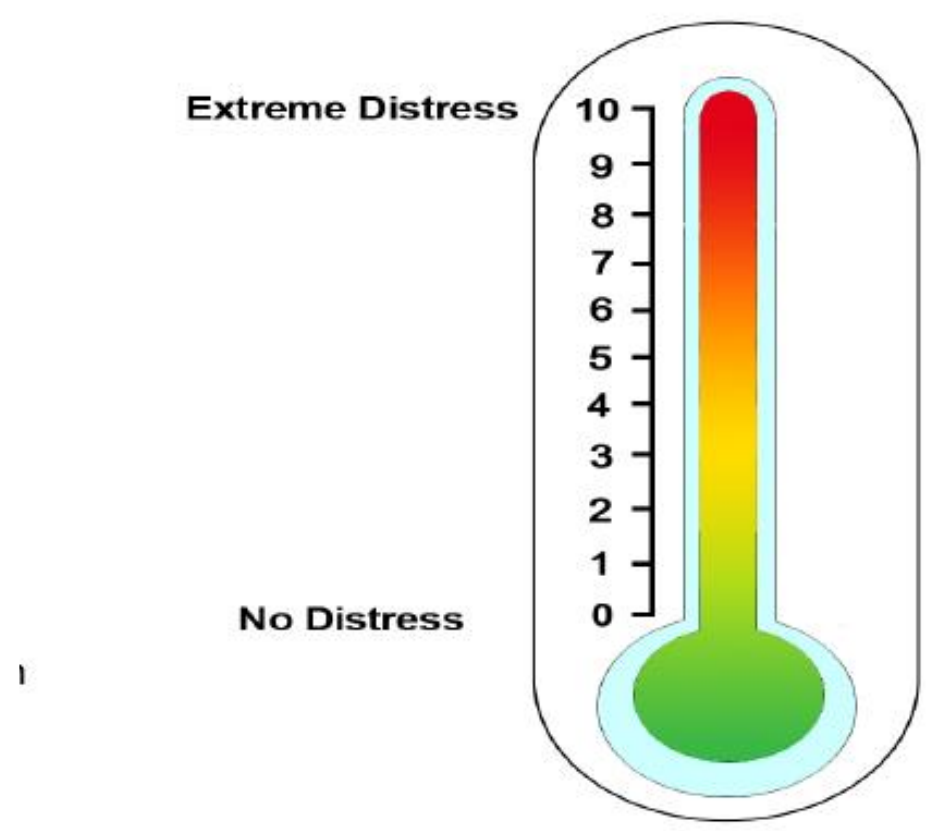

4. Were you warned that you might get confused after your operation?
a) Yes
b) No
c) I don't remember.

THAT IS THE END OF THE SURVEY. THANK YOU FOR YOUR TIME IN COMPLETING IT.

Do you have anything else you would like to say about this subject?

Please continue on a separate sheet if necessary. 
URN:

\section{Measuring the distress related to delirium - relative / friend / carer questionnaire}

Thank you for taking the time to complete this questionnaire. As part of a research project we are trying to find out more about how patients and their families and carers feel about some aspects of having an operation.

We estimate that it will take about 5 minutes to complete this survey. There are no right or wrong answers. Your responses are completely anonymous and confidential. They will not be seen by your doctors and nurses. We do not need your name.

When you have completed the questionnaire please hand it back to the researcher.

Thank you very much for your help in filling out the questionnaire. If you would like any further information about this research or if you have any questions at all please email xxx or call $\mathrm{xxx}$ 
URN:

\section{Delirium Experience Questionnaire - relative / friend / carer}

1. After their operation your relative / friend became confused. We know that this can be upsetting to see.

How distressed did it make you feel to see your relative / friend when they were confused?

Please mark how distressed you feel on the thermometer below.

0 is 'not at all distressed' and 10 is 'extremely distressed'.

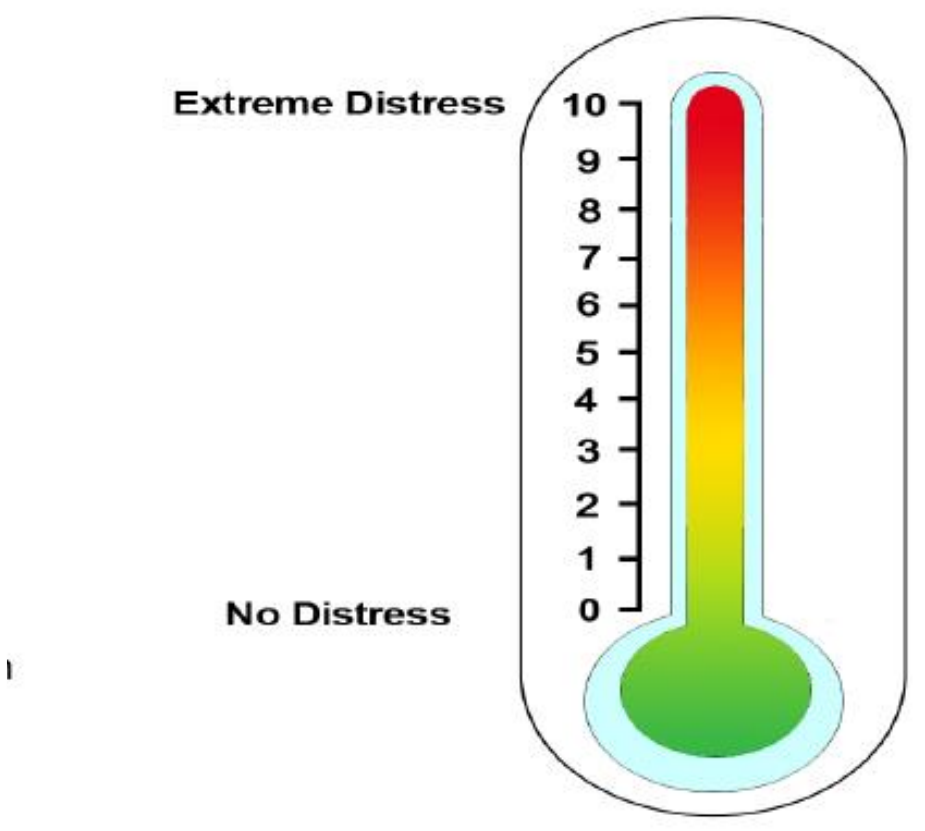

2. Were you warned that your friend/relative may get confused after their operation?
a) Yes
b) No
c) I can't remember 
3. Did anybody explain the confusion to you?

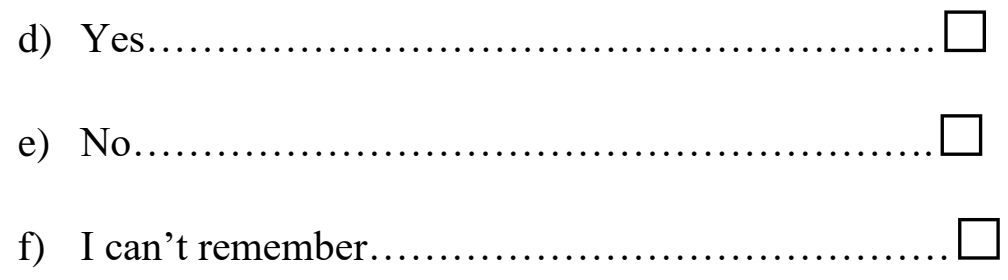

3. Please describe your relationship to the patient (e.g. daughter, son, niece, nephew, friend, neighbour etc)

\section{THAT IS THE END OF THE SURVEY. THANK YOU FOR YOUR TIME IN COMPLETING IT.}

Do you have anything else you would like to say about this subject? Please continue on a separate sheet if necessary. 
